\title{
UNA COINCIDÈNCIA TEXTUAL ENTRE LA TUHFA D'ANSELM TURMEDA/CABDALLĀH AL-TARJUMMĀN I EL TRACTAT NÚM. 21 DELS GERMANS DE LA PURESA Nova aportació a la qüestió de l'autenticitat de la Tuḥfa
}

\author{
Per \\ ROBERT BEIER \\ Universitat de Ratisbona (Regensburg)
}

En analitzar l'estil i el llenguatge de la Tuhfat al-adib $\pi$ al-radd 'alä ahl al-

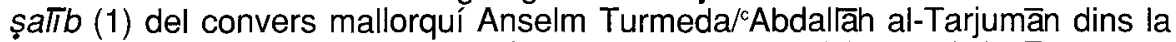
introducció a la primera edició crítica d'aquesta obra (2), Mikel de Epalza va destacar la heterogeneïtat estilística de l'obra i va discutir problemes d'autenticitat hicol.ligats. Resulta de la seva anàlisi que l'estil literari de la Tuhfa "puede ser calificado de malo con cierto fundamento", encara que hi hagi també trossos de prosa rimada «con cierta elegancia» (3). Són aquests trossos que ens han d'ocupar aquí. Examinats de més prop, se'n desprenen alguns detalls que poden aportar nova llum a la qüestió de la composició de la Tuḥfa.

\section{El fet}

Els trossos en qüestió són compostos, com s'ha dit, en prosa rimada $\left(s a f^{i}\right)$, estil culte típic de l'àrab i connotat amb discursos solemnes de diversos contingut's. Emprat en alguns llocs dins la Tuhfa, crida l'atenció pel viu contrast

(1) Vegeu-ne la traducció catalana per Mlkel de Epalza i ignasi Riera, Autobiografia i atac als partidaris de la Creu (Barcelona: Curial, 1978).

(2) Mikel de Epalza: La Tuhfa, autobiografía y polémica islámica contra el Cristianismo de 'Abdalăh alTarýumān (fray Anselmo Turmeda). Atti dell'Accademia Nazionale dei Lincei, an. 368 (Roma, 1971).

(3) Op. cit., p. 162s. 
que forma amb l'estil col-loquial, narratiu, anecdòtic que predomina en la major part de l'obra.

Passant per alt les ocasions on ocorre el saj en acumulacions de qualificatius polèmics dels cristians, disperses per tota la part dogmàtica de l'obra, s'observa la posició significativa que ocupen els trossos més coherents en saj dins el conjunt de l'obra. Es tracta precisament de tres ocurrències principals (4): el tros més llarg ocupa la primera plana de l'obra i n'és el pròleg; els altres dos trossos, que en realitat no passen d'una rengla i mig sengles, conclouen la primera part autobiogràfica-històrica i la segona part dogmàtica de l'obra respectivament. Són, doncs, col-locats tots tres en posició inicial o final, posicions de valor estratègic per a la composició literària de l'obra, formant-ne el contenidor compositiu.

Aquestes posicions, en qualsevol obra d'informació islàmica les ocupa normalment una invocació de Déu de tenor glorificador (tamj̄o) -la fórmula més convencional d'aquest tipus és la "basmalla» ("Bismillah al-Rahman alRahim», «En nom de Déu, el Clement, el Misericordiós»), que comunament encapçala tot escrit en àrab-. Per tant no és gaire estrany que també els tres trossos en qüestió siguin d'aquest tenor glorificador-tamijd de la religió islàmica tota entera el primer, tamiid en forma de benedicció del Profeta, la seva família i tots els seus companys els altres dos-, i que siguin compostos en saj", l'estil apte per excel-lència per a expressar el caràcter sublim de la llaor de Déu i del seu profeta.

Bastin aquestes poques observacions per aclarir la funció que acompleixen els trossos en saj dins la composició de la Tuhfa. Però dit això, es posa la qüestió de l'autenticitat dels trossos, tant més d'interés que és relacionada amb el problema més ampli de l'autenticitat de la Tuhfa, exhaustivament tractat per M. de Epalza en la seva introducció a l'obra (5). En altres paraules: es pot imaginar que el mallorquí Anselm Turmeda dominés a tal punt l'idioma àrab (6) de poder reproduir correctament el seu ideari i inventari formal i que ell mateix va compondre els trossos de tamjid en qüestió, tan estranys que siguin als procediments de la seva llengua nativa catalana? O més aviat s'ha sospitar que aquells hagin sortit de la ploma d'algun escriba àrab, potser l'hipotètic adaptador morisc de la Tuhfa del segle XVII? (7).

Amb un descobriment sorprenent espero que es pugui portar una mica de Ilum a aquesta qüestió. Es tracta d'una coincidència textual segurament no casual entre el tamiid introductori de la Tuhfa i un tros de tamĭd contingut dins el tractat (risāla) núm. 21 de l'Enciclopèdia dels Germans de la Puresa (Iṇwān al-Șafä).

\footnotetext{
(4) Op. cit., pp. 193, 271 i 497.

(5) Vegeu especialment op. cit., ps. 166 ss.

(6) Segons la seva pròpia affirmació en Tuhfa, op. cit., p. 231: «vaig aprendre perfectament l'àrab en només un any".

(7) Vegeu la introducció de M. de Epalza a op. cit., p. 168 i pàssim.
} 
Heus aquí els dos trossos de tamīd acarats:

Anselm Turmeda/`Abdallăh

al-Tarjumān, Tuhfa, p. 193:
Germans de la Puresa (Ihwān

al-Șafā'), Tadā'T al-h̆ayawānāt,

p. 64 : (8) («Discurs del quraisita»)

\section{Anàlisi}

D'aquesta comparació es desprén netament una relació de dependència quasi literal entre els dos trossos de text. És a dir amb més precisió que la Tuhfa depén de la Risāla, ja que la redacció d'aquesta és anterior a la d'aquella de quasi cinc segles. Des de la línia 1 fins a la línia 12 del text de la Tuhfa s'expressen les mateixes idees en el mateix ordre del text de la Risäla. Tres rengles $(1,4$ i 12) són fins $i$ tot idèntiques!

Les modificacions introduïdes en el text de la Tuhfa respecte a la font són lleugeres i no en canvien gaire la idea general. Tanmateix un examen detallat d'aquestes modificacions dóna resultats significatius. Sen' observen tres categories principals:

(1) Amplificacions: Són explicacions o descripcions addicionals, com de les posicions prescrites a les diverses estacions del pelegrinatge $\left(a l-r u k \bar{u}^{\circ}, 1.6\right.$; al-wuqūf I. 8), que falten al text original i no són gaire necessàries per a la

(8) Es tracta més precisament d'un apòleg titulat:

(Disputa dels animals contra l'home devant el Rei dels genis) que constitueix l'apèndix del tractat (risāla) núm. 21 de l'Enciclopédia dels Germans de la Puresa (Ihwā̄n al-Ṣafä'), una secta de místics a la Bàssora del segle X. L'edició utilitzada és la de Friedrich Dieterici, Die Philosophie bei den Arabern im X. Jahrhundert n. Chr., vol. 10 (Hildesheim, 1969, reproducció de l'edició Leipzig, 1869). 
comprensió. La inserció de la preposició calā, I. 8, i de la precisió wal-rukū cinda, I. 6, desfigura les metonimies originals ( $w$-al-ruk $\bar{u}^{c} w$-al-maqām, r. $6 ; w$ al-manābir $w$-al-hutab, I. 8), transformant-les en expressions de trivial concretesa. Cal afegir que tals insercions al text de la font no interrompen gaire l'ordre formal del sajc, ja que en aquest tipus de rima (prosa rimada), contràriament al funcionament de la rima als idiomes romanços, no s'han de comptar síl-labes.

(2) Variants fonètiques/semàntiques: (qur'ān/furqān, Is. 2, 3; variacions del

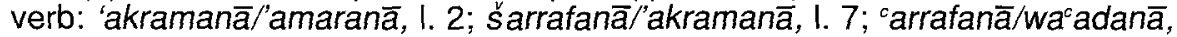
I. 14). Aquestes darreres variacions poden suggerir un goig innocent de l'autor d'experimentar amb les possibilitats combinatòries de la llengua. Semànticament, no canvien res al significat del conjunt. La gran quantitat de tals variants semàntiques rimants és un tret típic de l'àrab, resultant de les particularitats de la formació de paraules d'aquest idioma.

(3) Faltes òbvies: Falta l'article definit en țawāf, I. 5, i carafāt, I. 8; falta la vocal llarga en jama'ăt, r. 10 (jumu'at?). Una hipòtesi per a explicar aquestes faltes podria ser que siguin degudes a la comprensió oral deficient d'un individu que tingui dificultats a distingir entre consonants simples i geminades (falta de l'article assimilat) i entre vocals llargues i curtes. És curiós que aquests tipus de faltes ocorren per tot arreu al text de la Tuhfa. D'altra banda, entre els idiomes que desconeixen les dites distincions fonètiques són el català i el castellà. Consideracions aquestes que farien suposar que l'autor del tros en qüestió no fos probablement un arabòfon, sinó un parlant d'una llengua ibèrica, perquè no el mateix autor de l'obra, Anselm Turmeda?

A l'última part del tros l'autor es contenta de reprendre una sèrie de set conceptes clau de la glorificació del Profeta derivats del text del tractat (sunan,

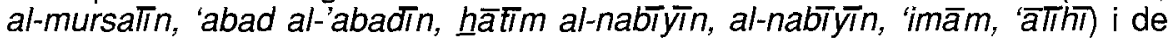
col-locar-los en un nou ordre. La resta de l'espai l'ompli amb altres frases estandartitzades pertanyents a l'elogi del Profeta, que però no poden ser derivades del tractat.

Una observació ulterior digna de ser destacada és la coincidència quasi literal de l'última frase del tros examinat de la Tuhfa, una benedicció del Profeta, la seva família i els seus companys, amb els altres dos trossos de tamjid de la Tuhfa que conclouen les dues parts principals de l'obra:

(II. 18, 19)

(fi de la primera part)

(fi del llibre)

Aqui es tracta òbviament de tres variants, totes en saj ${ }^{\circ}$, d'una mateixa frase que no pot ser inspirada del tros examinat del tractat dels Germans de la Puresa. Convé remarcar, però, que frases de tamjid com aquesta són talment 
convencionals, tant oral com literàriament, que seria un esforç ociós voler-ne descobrir una font.

\section{Conclusions}

Això no obstant, sembla establert amb prou plausibilitat que el tamjid introductori de la Tuhfa és un plagi literari del tamjid examinat del tractat núm. 21 de l'Enciclopèdia dels Germans de la Puresa. Ara bé, la significació d'aquest descobriment no sols és el fet que es tracta d'un plagi, sinó també que el plagiari és, amb tota probabilitat, Anselm Turmeda. El fet que ell, efectivament, utilitzà la mateixa font, un apòleg dins el dit tractat, per derivar-ne la matèria per una seva obra magistral en llengua catalana. la Disputa de l'Ase, li va meréixer, al 1914, un estudi detallat i, com a resultat, la condamnació global de l'obra i del seu autor per part de l'arabista Miguel Asín Palacios (9). Però també allunya la hipòtesi que un altre que ell mateix, 'Abdallah al-Tarjuman, autor de la Tuhfa, fos també l'autor d'aquest segon plagi del tractat en qüestió, suposició corroborada, de més, per algunes faltes característiques de grafia que ocorren al tros (10).

Aquest tros curt és l'únic exemple de dependència textual del tractat que poguí constatar, i és improbable que n'hi hagi altres, ja que l'ideari polèmic dels Germans de la Puresa no confronta en alguns punts fonamentals amb la polèmica ortodoxa de l'islam contra el cristianismo, representada per la Tuhfa (11). Quant al fet d'haver escollit precisament aquestes poques rengles per utilitzarles en la pròpia obra, revela una vegada més la gran intuició del convers mallorquí en matèries de la psicologia musulmana. No costa molt d'endevinar la funció apologètica del tros dins la Tuhfa i, per tant, el motiu que tenia el convers per copiar-lo. La intenció d'En Turmeda hi era òbviament de donar al seu auditori musulmà un tamjid dels més autèntics, i què podia trobar de millor, de més pur, de més convicent del "Discurs del quraisita», ja que Qurais s'anomena la tribu del mateix Profeta!

Pel que fa a la sinceritat de l'autor en pronunciar tals elogis, es podria sospitar que En Turmeda, en realitat, no feia altre que la paròdia de l'estil ampullós de tals textos en àrab. Però al proposar una tal hipòtesi s'ha de procedir amb molt de precaució, ja que això que als no àrabs pot semblar exaltat i fins ridícul en un tal text perquè no en comparteixen les evocacions psicolingüístiques, pot molt bé expressar per a un araboparlant i musulmà les emocions més sinceres i autèntiques del món, i les pot haver expressat també per En Turmeda!

Sigui això com vulgui, demostra En Turmeda amb la seva aplicació correcte de l'element compositiu del tamjid a la Tuhfa que no li costava gaire d'efectuar un canvi radical de perspectiva cultural (12), sempre suposat que ell en

(9) Miguel Asin Palacios, "El origen árabe de la "Disputa del Asno contra Fr. Anselmo Turmeda"», Revista de Filologia Española, 1 (1914), 1-51.

(10) Vegeu més amunt.

(11) Contràriament a l'ortodòxia islàmica, els Germans de la Puresa reconeixen, per exemple, l'autenticitat de les Escriptures i la crucificació de Jesús.

(12) Sobre el perspectivisme en l'obra de Turmeda vegeu l'anàlisi perspicaç de Rafael Alemany Ferrer, "Turmeda/Abdallà o el "perspectivisme" com a pràctica vital i/o literària", Miscel/lania Joan Fuster (Montserrat, 1989), 37-57. 
sigui realment l'autor. I partint de la convicció, per bones raons, que això és cert, per què no atribuir-li també aquelles parts de la Tuhfa que encara resulta difícil imaginar que van ser compostes per un ex-frare franciscà?

Del descobriment d'una cóincidència textual entre la Tuhfa d'Anselm Turmeda/'Abdallāh al-Tarjumān i el tractat núm. 21 de l'Enciclopèdia dels Germans de la Puresa s'ha desprès una sèrie d'hipòtesis que, com a hipòtesis, tan plausibles que siguin, no poden constituir cap prova definitiva per un altra hipòtesi. Però del cert poden corroborar la tèsi de M. de Epalza (13) que tendeix a atribuir la totalitat de la Tuhfa a Anselm Turmeda/cAbdallăh al-Tarjumān.

(13) M. de Epalza: op. cit., p. 168. 